Gut, 1963, 4, 8

\title{
Post-operative absorption of water from the small intestine
}

\author{
L. F. TINCKLER AND W. KULKE \\ From the Department of Surgery, University of Liverpool, and \\ Liverpool Radium Institute
}

EDITORIAL SYNOPSIS An investigation of water absorption from the small intestine after abdominal surgery has produced more detailed information on the effect of trauma on the motility of the gastro-intestinal tract. Whereas after trauma the equilibration of tritiated water given by the oral and colonic routes is retarded, given by the jejunal route it is normal.

Trauma has a definite effect on the motility of the gastro-intestinal tract, whether that trauma be accidental or surgical. Vaughan and Thorek (1939) refer to a traumatic paresis of the alimentary tract that lasts for 24 to 48 hours after abdominal surgery. Gastric stasis following operation is well recognized, and the post-operative management of the patient takes this into account by withholding or giving fluids sparingly by mouth for a time until there is evidence of a return of gastric emptying.

In Smith's (1956) experience, necropsy on subjects dying after major injury often revealed gaseous distension of the stomach and proximal colon. Sheehan (1948) reported similar findings in patients dying in obstetric shock.

The emptying rate of the stomach was reduced in rats subjected to muscular ischaemia by means of a tourniquet according to Whitely and Green (1952). In their experiments motility was assessed by adding barium to the animals' feed before applying trauma, then following the progress of the barium radiographically.

Whether or not this alteration of motility after trauma is associated with a change in the capacity of the gastro-intestinal tract to absorb has been investigated by several workers. The issue is of some importance as it concerns the route for administering fluid and nutrients to injured and postoperative subjects.

Howard (1955), during the Korean war, studied the absorption of water given by mouth to battle casualties. Using heavy water (deuterium oxide) as a tracer substance, he followed its absorption by estimating its content in serial venous blood samples taken at intervals after ingestion. In normal control subjects he found that water rapidly entered the circulation from the gastro-intestinal tract and that equilibration of deuterium oxide throughout the body was reached within two or three hours. After moderate burns or wounds of the chest and extremities absorption of deuterium oxide was impaired but remained much more rapid than after abdominal injury. After intra-abdominal injuries deuterium oxide absorption from the gastrointestinal tract was markedly delayed and this delay persisted for several days.

Again using deuterium oxide, Drawhorn and Howard (1957) investigated the absorption of water given to subjects orally or rectally after operation and found that absorption by either route was adversely affected. In each subject $100 \mathrm{~g}$. of deuterium oxide was given either by mouth or rectally, and blood specimens were taken at intervals for deuterium estimation both before and after operation. Patients investigated had undergone herniorrhaphy, gastrectomy, and thoracotomy. It was concluded that absorption of water from the gastro-intestinal tract was adversely affected by trauma, regardless of the route by which it was administered; the delay in absorption was of mild degree and of short duration except after intra-abdominal or intrathoracic trauma when it might be severe and prolonged.

Howard and Davies (1954), carrying out a similar investigation on patients who had undergone appendicectomy or herniorrhaphy under spinal anaesthesia, found that the equilibration time of deuterium oxide given by mouth was prolonged in the patients who had been operated upon within the preceding 24 hours.

The following is an account of an investigation of water absorption from the small intestine after abdominal surgery. 
METHOD

During the course of an abdominal operation a long polythene tube (gauge 3 ) was introduced by the anaesthetist down the patient's oesophagus into the stomach from whence it was manipulated by the surgeon to about one third of the way down the small bowel, where it remained for the post-operative recovery period.

At some time during the first post-operative 24 hours, a small amount of tritiated water was syringed down the polythene tube into the small bowel of each patient and followed by a similar quantity of saline to ensure complete delivery of all the radioactive water into the bowel. Serial specimens of venous blood were then taken at intervals of about 10, 20, 30 minutes and one, two, three, and four hours. In each case $10 \mathrm{ml}$. of tritiated water of 0.4 or 0.5 millicurie radioactivity was used. Plasma water was obtained from each blood specimen by centrifuging down the cells, pipetting off the plasma, and then precipitating the plasma protein with $100 \%$ trichloracetic acid using $0.1 \mathrm{ml}$. of acid to each millilitre of plasma. Clear plasma water was then obtained by centrifuging down the precipitated protein and the radioactivity of each specimen assayed by coincidence liquid scintillation counting.

A standard was obtained by scintillation counting a sample of the tritiated water administered to each patient, and the tritium content of the plasma water expressed as a percentage of the total tritium administered per litre of plasma water. Individual results are shown in the graphs and their legends.

\section{RESULTS}

Data were obtained from seven patients. In five tritiated water was given into the jejunum and in two it was administered intravenously. The equilibration of tritium throughout the body water space in each case is shown graphically in Figs. 1 to 7. A tritium absorption equilibration graph was obtained from one patient whose jejunal tube was left in situ until the eighth post-operative day (Fig. 1), by which time, as the patient was eating and drinking, normal absorption from the small bowel was assumed. This result was obtained as a control for comparison with the early post-operative tritium equilibration results (Figs. 2 to 5). These show that the uptake of tritium from the small bowel on the first post-operative day after major abdominal surgery is rapid, and equilibration throughout the body is reached within two hours, circumstances which are in all respects similar to the pattern of
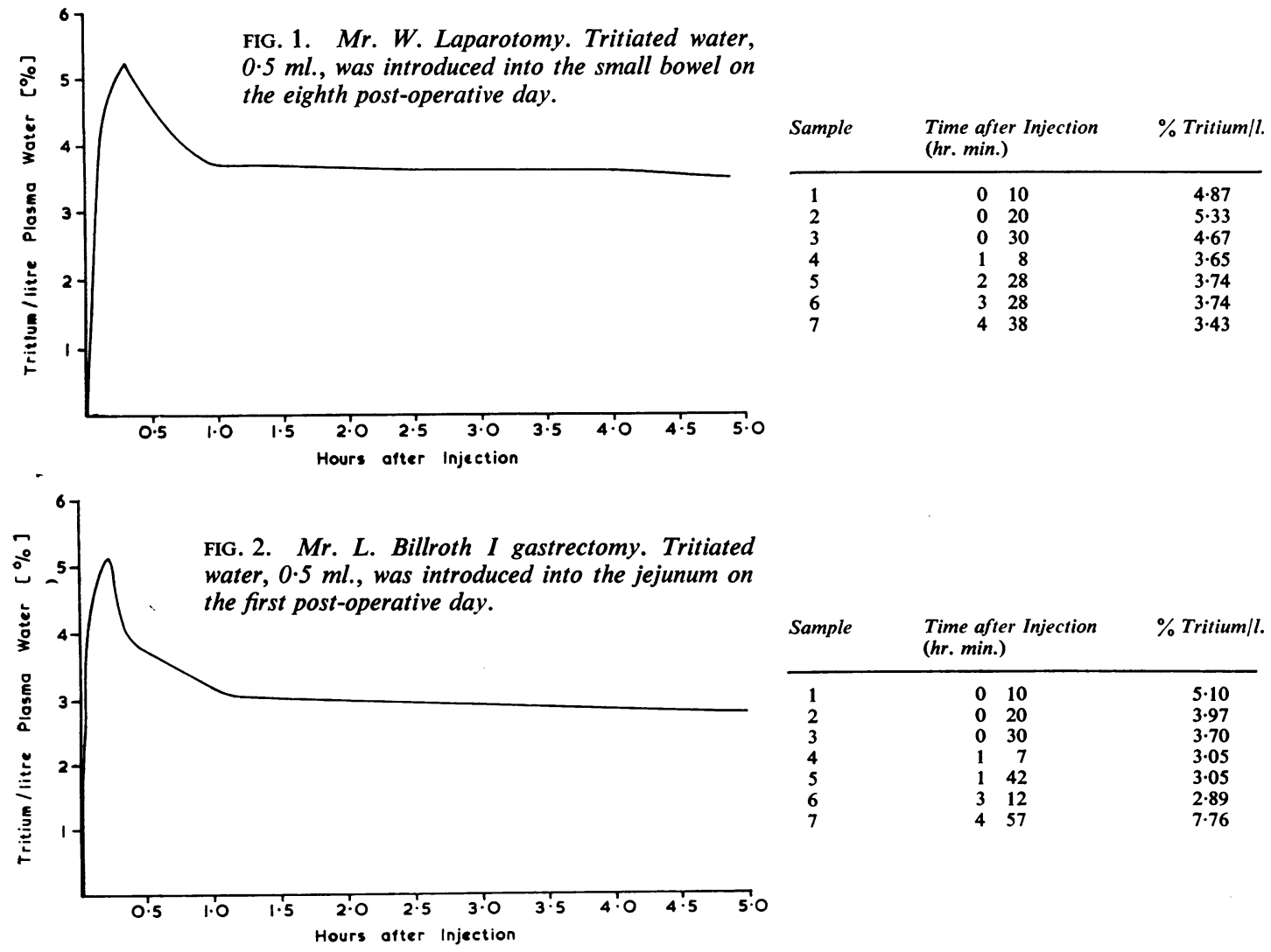


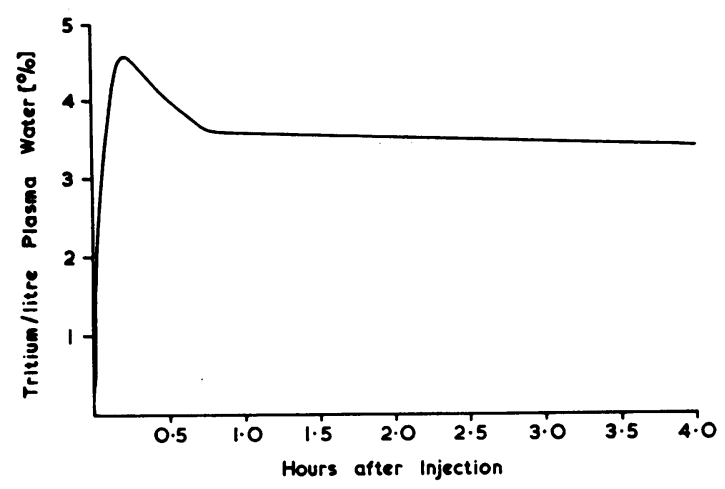

FIG. 3. Mr. W. Gastrectomy and transverse colectomy. Tritiated water, $0.5 \mathrm{ml}$., was given into the jejunum on the first post-operative day.

\begin{tabular}{lccc} 
Sample & Time after Injection (hr. min.) & \% Tritium/l. \\
\hline 1 & 0 & 5 & $3 \cdot 29$ \\
2 & 0 & 15 & $4 \cdot 64$ \\
3 & 0 & 25 & $4 \cdot 17$ \\
4 & 0 & 45 & $3 \cdot 64$ \\
5 & 1 & 45 & $3 \cdot 58$ \\
6 & 2 & 45 & $3 \cdot 75$ \\
7 & 3 & 45 & $3 \cdot 23$
\end{tabular}

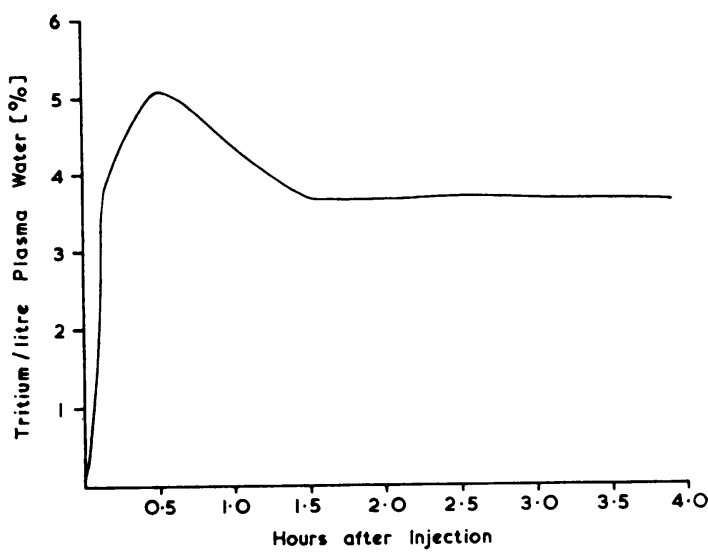

FIG. 5. Mr. T. Laparotomy. Tritiated water, $0.5 \mathrm{ml}$., was introduced into the small bowel on the first post-operative day.

\begin{tabular}{|c|c|c|}
\hline Sample & Time after Injection (hr. min.) & $\%$ Tritium $/$ l. \\
\hline 1 & $\begin{array}{ll}0 & 10\end{array}$ & $3 \cdot 77$ \\
\hline 2 & 020 & $4 \cdot 50$ \\
\hline 3 & $\begin{array}{ll}0 & 30\end{array}$ & 5.09 \\
\hline 4 & 10 & 4.44 \\
\hline 5 & 127 & 3.79 \\
\hline 6 & 227 & 3.69 \\
\hline 7 & 332 & 3.73 \\
\hline
\end{tabular}

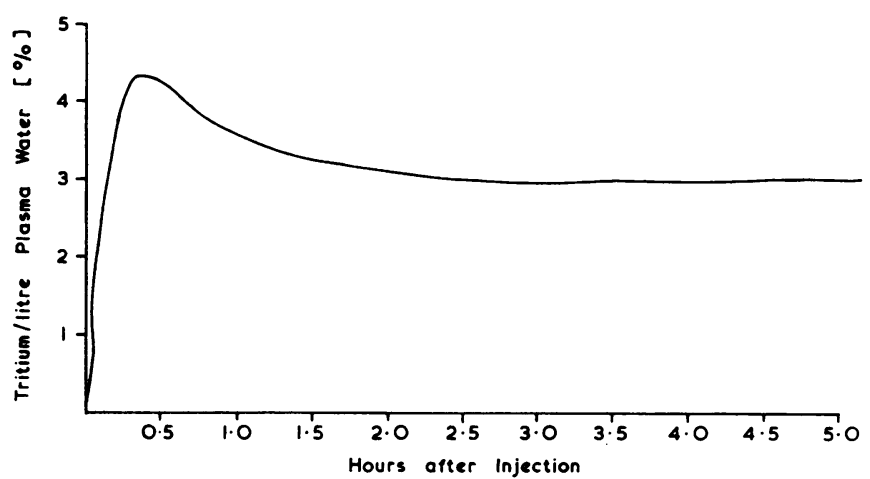

FIG. 4. Mr. P. Gastrectomy. Tritiated water, $0.5 \mathrm{ml}$., was introduced into the jejunum on the first post-operative day.

\begin{tabular}{|c|c|c|}
\hline Sample & Time after Injection (hr. min.) & $\%$ Tritium $/$ l. \\
\hline 1 & $\begin{array}{ll}0 & 13\end{array}$ & 3.48 \\
\hline 2 & 020 & $4 \cdot 34$ \\
\hline 3 & $\begin{array}{ll}0 & 30\end{array}$ & 4.29 \\
\hline 4 & $\begin{array}{ll}0 & 48\end{array}$ & 3.75 \\
\hline 5 & 152 & 3.30 \\
\hline 6 & 248 & 3.03 \\
\hline 7 & $\begin{array}{ll}3 & 48\end{array}$ & 3.07 \\
\hline 8 & 453 & $3 \cdot 22$ \\
\hline
\end{tabular}




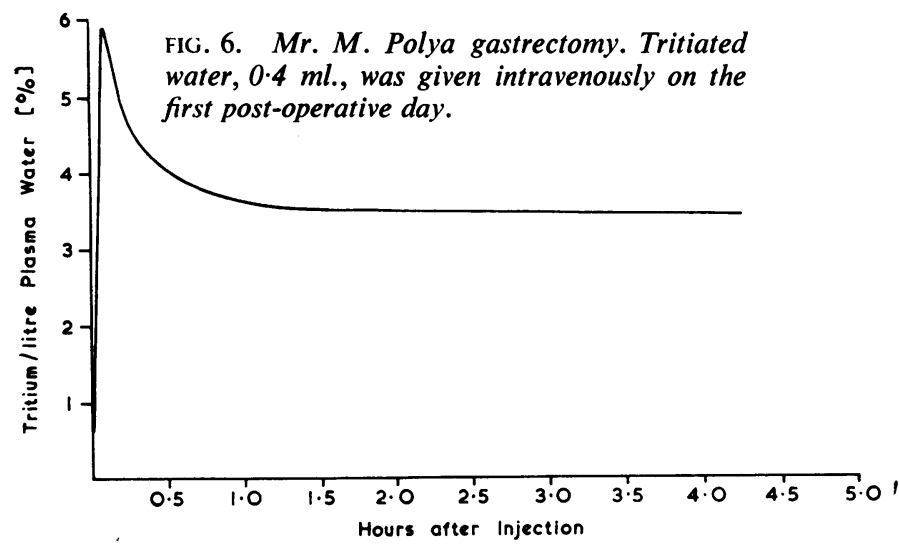

FIG. 7. Mr. P. Normal control. Tritiated water, $0.5 \mathrm{ml}$, was given intravenously.

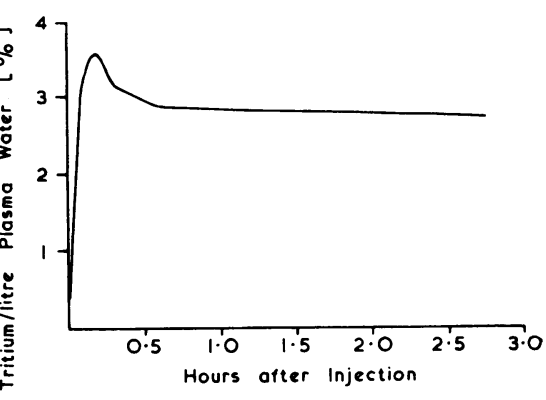

\begin{tabular}{cccc} 
Sample & Time after Injection (hr. min.) & \% Tritium/l. \\
\hline 1 & 0 & 5 & 5.94 \\
2 & 0 & 15 & 4.63 \\
3 & 0 & 25 & 4.24 \\
4 & 0 & 45 & 3.82 \\
5 & 1 & 15 & 3.57 \\
6 & 2 & 15 & 3.40 \\
7 & 3 & 15 & 3.46 \\
8 & 4 & 15 & 3.45
\end{tabular}

\begin{tabular}{lcrc} 
Sample & $\begin{array}{l}\text { Time after Injection } \\
\text { (hr. min.) }\end{array}$ & $\%$ Tritium/l. \\
\hline 1 & 0 & 10 & $3 \cdot 57$ \\
2 & 0 & 20 & $3 \cdot 15$ \\
3 & 0 & 42 & $2 \cdot 89$ \\
4 & 1 & 12 & $2 \cdot 87$ \\
5 & 2 & 2 & $2 \cdot 80$
\end{tabular}

uptake exhibited by the normal small bowel (Fig. 1). Comparison of the equilibration of tritium when given intravenously on the first post-operative day (Fig. 6) and that of a control subject (Fig. 7) shows that the rates are again similar, equilibration taking place within two hours.

\section{DISCUSSION}

Tritium is the radioactive isotope of hydrogen (atomic weight 3). It has a radioactive half-life of 10 years and a biological half-life of nine days. Biologically it is handled in the body in the same manner as hydrogen (Pinson and Addison, 1950). Accordingly it can be used as a tracer substance to follow the movement of water throughout the body.

Equilibration of tritium, that is, its equable distribution throughout the total body water space absorbed from the gut, depends on several factors, namely, motility of the gastro-intestinal tract, absorption across the mucous membrane of the bowel, intravascular circulation, and diffusion throughout the extracellular and intracellular fluid compartments (Howard, 1955). In this investigation it was shown that when given intravenously equilibration of tritium is as rapid in the early postoperative period as under normal circumstances, so that distribution throughout the body water spaces is not affected by a recent incident of trauma, once tritium has reached the circulation. Any difference in the equilibration rate of tritium administered via the gastro-intestinal tract early after operation as compared with the normal must therefore be due to changes in gastro-intestinal motility, mucosal absorption, or both. Howard (1955) and Drawhorn and Howard (1957) have demonstrated in equilibration graphs the shift to the right in deuterium oxide absorption experiments from the stomach and colon after trauma, indicating a delay in absorption of water from these sites. Comparable observations in this investigation on the capacity of the small bowel to absorb tritium show no such alteration in this capacity after operation. Strictly speaking, these equilibration values indicate no more than the passage of tritium molecules from the bowel lumen into the body and do not necessarily reflect a net gain of fluid; they might be due to a random diffusion of molecules from the gut into the circulation with an equal amount leaving the body and appearing in the intestinal contents. However, this is unlikely to be so, as according to Visscher, Fletcher, Carr, Gregor, Burley, and Booker (1944), the passage of water from the bowel lumen into the circulation is by a dynamic process mediated by the intestinal mucosa and not by simple diffusion. The shape and time values of the equilibration graphs obtained on the first day after operation from the small intestine are similar to those of the normal 
control and suggest that fluid is actively absorbed from that site in the early post-operative period.

Furthermore patients can be kept in a satisfactory state of hydration during post-operative recovery by means of small bowel tube feeding, a method of management which has its supporters for patients recovering from gastric surgery (Lee, 1957; McDonald, 1954).

The finding that equilibration from the small bowel after trauma is normal, in contradistinction to the retarded equilibration when fluid is given orally or by colonic instillation, is of interest in view of the observations of Wells, Rawlinson, Tinckler, Jones, and Saunders (1961) on postoperative gastro-intestinal motility; these demonstrated that whereas some degree of gastric and colonic inertia is invariable after abdominal surgery, small bowel movement continues as indicated by ascultation of bowel sounds, balloon kymography, and the passage of barium followed radiologically.
It is a pleasure to acknowledge our indebtedness to Mr. Russell Herbert and Miss Shepherd, of the Radio Isotope Department of the Liverpool Radium Institute, for assaying the radioactivity of the plasma water specimens; also to Miss Barbara Duckworth and Mr. W. Lee and the staff of the Central Photographic Department, Liverpool University, for the illustrations.

\section{REFERENCES}

Drawhorn C. W., and Howard, J. M. (1957). Ann. Surg., 146, 239-245. Howard, J. M. (1955). Surg. Gynec. Obstet., 100, 69-77.

- and Davies, J. H. (1954). Surgery, 36, 1127-1131.

Lee, M. (1957). Postgrad. med. J., 33, 78-82.

McDonald, H. A. (1954). Lancet, 1, 1007.

Pinson, E. A., and Addison, E. C. (1950). Abstract Amer. J. Physiol., 163,741 .

Sheehan, H. L. (1948). Lancet, 1, 1-7.

Smith, G. A. (1956). J. Amer. med. Ass., 160, 266-268.

Vaughan, R. T., and Thorek, P. (1939). Amer. J. Surg., 45, 230-234.

Visscher, M. B., Fletcher, E. S., Carr, C. W., Gregor, H. P., Burlay, M. S., and Booker, D. E. (1944). Amer. J. Physiol., 142, 550

Wells, C. A., Rawlinson, K., Tinckler, L., Jones, H., and Saunders, J. (1961). Lancet, 2, 136-137.

Whitely, W. J., and Green, H. N. (1952). J. Path. Bact., 64. 224-228. 